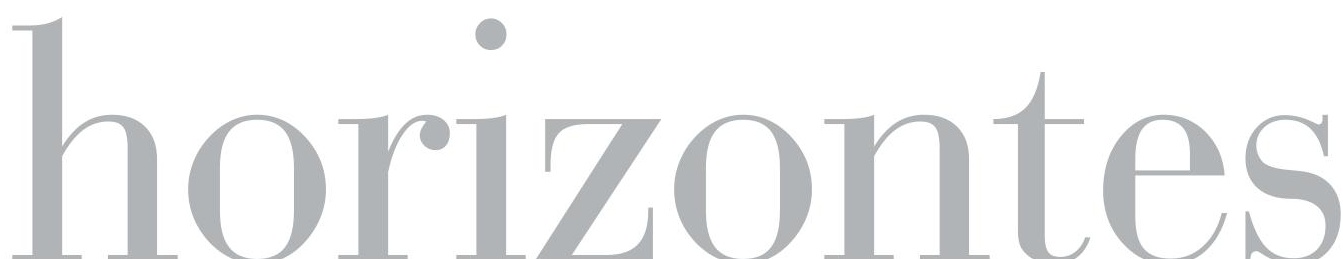





\section{Reflexiones sobre experiencias de abandono de escuela secundaria y doctorado en Argentina. Modos de cierre $\mathbf{y}$ condicionantes individuales $\mathbf{e}$ institucionales $^{1}$}

Ana Maria Bartolini ${ }^{2}$

Universidad Autónoma de Entre Ríos (UADER); Universidad Nacional

de Entre Ríos (UNER), Argentina

lastresana@arnet.com.ar

Graciela Gerlo ${ }^{3}$

Universidad Autónoma de Entre Ríos (UADER); Universidad Católica Argentina Santa María de los Buenos Aires (UCA), Argentina

ggerlo_1kuhn6@hotmail.com

Recibido: 25 de enero de 2016

Aceptado: 12 de mayo de 2016

Disponible en línea: 20 de diciembre de 2016

Este artículo de reflexión surge de las investigaciones correspondientes a dos tesis de posgrado (maestría y doctorado), sin financiamiento institucional.

2 Doctora en Educación, Universidad de San Andrés (Argentina). Profesora por concurso de "Seminario de Tesis" y de "Metodología de la Investigación Archivística", Universidad Autónoma de Entre Ríos (UADER), y docente, Facultad de Ciencias de la Educación, Universidad Nacional de Entre Ríos (UNER) (Argentina).

3 Magister en Salud Mental, UNER. Profesora de enseñanza elemental y de enseñanza superior en Ciencias de la Educación, UADER (Argentina). 


\title{
Reflexiones sobre experiencias de abandono de escuela secundaria y doctorado en Argentina. Modos de cierre y condicionantes individuales e institucionales
}

\section{Resumen}

El artículo reflexiona críticamente sobre el abandono educativo, comparando desertores de escuelas secundarias y de programas doctorales en la República Argentina. La perspectiva teórica integra las categorías de deserción voluntaria y exclusión académica de Tinto (1989), con los conceptos de habitus y violencia simbólica de Bourdieu (Bourdieu y Passeron, 1981). Las reflexiones surgen del análisis interpretativo de experiencias de abandono en escuelas secundarias y en doctorados. Este fue realizado mediante la relectura, una nueva codificación y categorización del material empírico proveniente de dos tesis de posgrado, con el objetivo de comparar situaciones de abandono educativo que presentan más semejanzas que diferencias. Los resultados describen habitus auto obstaculizadores de los desertores, modos de cierre del abandono y condicionantes institucionales. Se concluye que: el abandono educativo es resultado de un proceso que niega, encubre y minimiza; la exclusión académica predominó mientras que la deserción voluntaria fue excepcionalmente hallada; los desertores desplegaron estrategias individuales, incluso persistir varios años a pesar de obstáculos institucionales, postergaciones personales y efectos nocivos en la salud mental.

Palabras clave: experiencias de abandono; escuela secundaria; doctorado; responsabilidad institucional

\section{Reflections on High School and Doctoral Student Attrition Experiences in Argentina. Closing Modes, and Individual and Institutional Constraints}

\begin{abstract}
The article reflects critically on school attrition, comparing high school and doctoral dropout rates in Argentina. The theoretical perspective integrates the categories of voluntary attrition and academic exclusion of Tinto (1989) with the concepts of habitus and symbolic violence of Bourdieu (Bourdieu and Passeron, 1981). The reflections arise from the interpretative analysis of attrition experiences in high schools and doctoral programs. This was done by rereading, and making a new coding and categorization of empirical material from two graduate theses in order to compare student attrition situation that have more similarities than differences. Results describe self-sabotaging habitus of dropouts, attrition closing modes, and institutional constraints. This work allows to conclude that student attrition is the result of a process that denies, conceals and minimizes; academic exclusion predominated, while voluntary attrition was exceptionally found. Dropouts used individual strategies, even persisting for several years despite institutional obstacles, personal postponements, and harmful effects on mental health.
\end{abstract}

Keywords: student attrition experiences; high school; doctoral program; institutional responsibility

\section{Reflexões sobre experiências de abandono no ensino médio e doutorado na Argentina. Modos de fechamento e constrangimentos individuais e institucionais}

\section{Resumo}

O artigo reflete criticamente sobre a evasão escolar, comparando abandonadores de escolas secundárias e de programas de doutoramento na República Argentina. A perspectiva teórica integra as categorias evasão voluntaria e exclusão acadêmica de Tinto (1989), com os conceitos de habitus e violência simbólica de Bourdieu (Bourdieu e Passeron, 1981). As reflexões aparecem na análise interpretativa de experiências de abandono em escolas secundarias e em doutoramentos. Ele foi realizado mediante releitura, nova codificação e categorização de material empírico provindo de duas teses de pós-graduação, com objetivo de comparar situações de abandono escolar que apresentam mais semelhanças do que diferenças. Os resultados descrevem habitus autoobstaculizadores dos alunos que abandonam, modos de fechamento do abandono e condicionantes institucionais. Conclui-se que a evasão escolar é resultado de um processo que nega, esconde e minimiza; a exclusão académica predominou entanto que a evasão voluntária foi excepcionalmente encontrada; os abandonadores despregam estratégias individuais, mesmo persistirem vários anos a pesar de obstáculos institucionais, adiamentos pessoais e efeitos nocivos na saúde mental.

Palavras-chave: experiências de abandono; ensino médio; doutoramento; responsabilidade institucional 


\section{Introducción}

El objetivo de este artículo es reflexionar desde una perspectiva crítica sobre el funcionamiento de la educación formal en la sociedad argentina contemporánea, comparando casos de abandono de escuelas secundarias y de programas doctorales en la República Argentina.

El texto surge a propósito de los hallazgos de dos tesis de posgrado cuyo cotejo pone al descubierto las similitudes en procesos de abandono en dos niveles educativos, que, a simple vista, parecen de naturaleza diferente. Esto inspiró una producción que trasciende el nivel de la comunicación de resultados - validados oportunamente-, para inscribirse en el ámbito de la reflexión.

El aporte de este artículo no consiste en informar lo hallado en las investigaciones, sino en estas teorizaciones que describen funcionamientos institucionales y los cotejan con lo que correspondería a la misión educativa que manifiestamente asumen estas organizaciones. Los enfoques sociales criticos no son éticamente neutros, como tampoco lo son las prácticas sociales; por eso se recogen evidencias empíricas, se las comunica asépticamente, al tiempo que se desnudan los valores que suponen y se ponen explícitamente en juego valoraciones cuando se reflexiona acerca de ellas.

En la República Argentina se destinan recursos significativos a la formación en los diferentes niveles educativos, sin embargo, se descuidan aspectos que inciden en forma determinante en los resultados. Son numerosos los estudios referidos a la alta tasa de abandono, tanto en secundario como en doctorado -especialmente en ciencias sociales y humanas-.

Los datos estadísticos del Censo Nacional de Población, Hogares y Viviendas 2010 (Instituto Nacional de Estadística y Censo, 2010), en relación con la jurisdicción investigada -Entre Ríos, República Argentina- señalan que, a pesar de la obligatoriedad del nivel secundario, el $43 \%$ del total de población que en algún momento concurrió a la escuela secundaria, no la completó. 
En relación con el abandono doctoral, los autores argentinos consultados ${ }^{4}$ informan que las cifras oscilan entre el $85,2 \%$ y el $94 \%$ (Barsky, 1997, 1999; Fernández Lamarra, 2003; García de Fanelli y Jeppesen, 2004; Jeppesen, Nelson y Guerrini, 2004; Carlino, 2005; Jeppesen citado en Marquís y Toribio, 2006; Marquís y Toribio, 2006; Pérez Lindo y Noto, 2007).

Este artículo reconoce antecedentes de teóricos e investigaciones internacionales y nacionales que demandan el estudio del abandono, bajo perspectivas microsociales y cualitativas, en las cuales se recuperen las trayectorias de los sujetos y las significaciones asignadas por ellos. A su vez, son escasas las investigaciones que exploran las experiencias secundarias y doctorales completas e incompletas (Bowen y Rudenstine, 1992; Tinto, 1993; Becher, 2001; Krotsch, 2003; Barsky, Sigal y Dávila, 2004; Dussel, 2004; Marquís y Toribio, 2006; Chavez, 2009; Escudero Muñoz, González González y Martínez Domínguez, 2009; Poggi y Tenti Fanfani, 2009; Ehrenberg, Zuckerman, Groen y Brucker, 2010).

El abandono como objeto de estudio plantea diferentes perspectivas analíticas. Desde un punto de vista individual, desertar significa no completar un curso de acción o no conseguir una meta deseada por la que se ingresó a la institución. En este caso particular, el concepto alude a las situaciones de abandono estudiantil antes de la finalización de un nivel educativo.

Sin embargo, se tardó en descubrir que el término 'deserción' designaba comportamientos muy diferentes: la exclusión académica y la deserción voluntaria, formas diversas del abandono o desgaste (attrition) educativo (Tinto, 1989, 1993).

La exclusión académica señala al abandono resultante de insuficientes $-o$ inexistentes- intervenciones institucionales destinadas a generar todas las oportunidades necesarias para que los estudiantes

Del Bello informó, por ejemplo, que la tasa de egreso de los posgrados argentinos es del $12,8 \%$ en las universidades privadas y del 10,7\% en las públicas. Dicho dato fue expresado en la presentación del libro de Del Bello, Barsky y Giménez (2007), en el marco del $3^{\circ}$ Seminario de Investigación en las Universidades Privadas, celebrado el 25 y 26 de septiembre de 2007. 
que lo deseen finalicen sus estudios; mientras que la deserción voluntaria se refiere al abandono como producto de una elección personal del estudiante. Es por esto que la deserción necesita analizarse desde varias perspectivas: estudiante, grupo, tiempo e institución.

El proceso de deserción varía también según los grupos de estudiantes y las etapas del nivel y de la carrera en la que sucede. La diversidad de contextos de origen de los alumnos representa un problema, en tanto existen numerosas situaciones que los ponen en desventaja -trabajar, sentirse ajenos a la dinámica educativa, etc.-.

Desde la perspectiva de la institución, es necesario identificar, entre los numerosos tipos de abandono, cuáles merecen preocupación e intervención institucional porque se producen por ineficiencia del sistema. Al aceptar individualidades, se establece una mayor responsabilidad de asegurar que los estudiantes cuenten con suficientes oportunidades para completar sus estudios. El fuerte compromiso con los resultados de los alumnos es un ethos de cuidado ${ }^{5}$ reconocible que trasluce el carácter de la vida institucional. Por lo tanto, la retención exitosa depende de la construcción de comunidades en las que los estudiantes se involucren y tengan voz durante el proceso educativo.

El sistema educativo requiere ser mirado críticamente para identificar el grado de presencia de este ethos de cuidado en las comunidades educativas. Esta mirada debe permitir desnaturalizar construcciones sociales en pos de superar condiciones dañinas para sus miembros. Berreman (citado en De Souza Minayo, 2009) denomina "región interior' a la parte intima de la vivencia de una comunidad, pero cualquier grupo humano guarda sus secretos, su lado oficial y tiene su estrategia comportamental de todos los días" (pp. 178-179). Esta estrategia permite mantener la cohesión grupal a pesar de los conflictos internos, demarcando zonas prohibidas para lo que no puede ser dicho. El investigador debe saber que "ningún grupo dirá totalmente la verdad sobre su realidad social" (p. 179).

Prácticas de la cultura escolar fuertemente arraigadas en la valoración de toda acción que contribuya al bienestar y promoción del alumnado. 
Por esta razón, si se pretende conocer los secretos del funcionamiento de las comunidades, en este caso las escolares y académico-disciplinares, "la mejor información" la brindan quienes han saltado el cerco de la "región interior" y se han liberado de la presión grupal ejercida en favor de la cohesión. Escuchar a quienes han salido o han sido excluidos del sistema es la mejor vía para revisar las reglas de juego vigentes, $\mathrm{y}$ ha sido el camino elegido en este artículo.

En consecuencia, las reflexiones sobre dichas reglas de juego parten del análisis interpretativo de los casos de abandono en los dos niveles educativos estudiados, que constituyeron la base empírica en dos tesis de posgrado. Una de ellas corresponde al doctorado en Educación de la Universidad de San Andrés y se titula Persistencia y desgaste doctoral. Un estudio en ciencias de la educación y ciencias experimentales (Bartolini, 2013). La otra pertenece a la maestría en Salud Mental de la Universidad Nacional de Entre Ríos, y se denomina Hacia la comprensión del doloroso proceso de construcción de la deserción de la escuela secundaria (Gerlo, 2014) ${ }^{6}$.

El análisis interpretativo fue realizado mediante la relectura de los datos y una nueva codificación y categorización -habitus, modos de cierre, condicionantes institucionales- en virtud del objetivo propuesto de comparar situaciones de abandono educativo.

Este análisis reflexivo considera los particulares modos de inserción de los dos niveles dentro del sistema educativo argentino y los pone en tensión con los conceptos de exclusión académica y de deserción voluntaria (Tinto, 1989). En relación con estas dos variantes del abandono, y aportando a la diferenciación teórica, se observa que la exclusión académica constituye una forma de injerencia de terceros

6 Las dos tesis que proveen los referentes empíricos a estas reflexiones seleccionaron muestras de tipo cualitativo. En el nivel secundario se analizaron ocho experiencias de abandono, a partir de los relatos de sus protagonistas: adolescentes de clases sociales pobres. En relación con el estudio sobre desgaste doctoral se señala que los programas doctorales son la vía rápida para la formación y el entrenamiento de los investigadores. La muestra cualitativa se conformó con 23 desertores provenientes de cuatro doctorados de universidades nacionales argentinas. Tres de ellos eran personalizados y uno estructurado. Los personalizados cuentan con cursos y actividades que culminan con la tesis y se organizan en forma diferente y particular para cada doctorando; mientras que los estructurados funcionan a partir de una oferta cerrada de cursos y actividades sucesivas, además de una tesis. Los sujetos respondieron un cuestionario autoadministrado, en tanto que 14 de ellos fueron entrevistados en profundidad. 
sobre el recorrido educativo del estudiante, pues se trata de una intervención impuesta al sujeto del proceso que voluntariamente participa de la oferta educativa. La presencia voluntaria de un estudiante muestra la existencia de dos proyectos simultáneos: uno personal y uno social. Este último es el proyecto colectivo de cohesión social y legitima el derecho de la sociedad a intervenir en los individuos para socializarlos y adaptarlos a las pautas compartidas. Cuando se acepta someterse a esa intervención es porque hay apropiación de objetivos de formación y se los considera beneficiosos; entonces pasa a convertirse en parte del proyecto personal. Si en estas circunstancias la escuela opera mecanismos de selección estudiantil y excluye a los interesados en el proyecto escolar colectivo, provoca frustración en tanto obstaculiza el logro de metas personales. Descripta así, la exclusión sería una modalidad de violencia social, con todas las connotaciones que esta categoría tiene (Peyrú y Corsi, 2007).

En relación con el concepto de deserción voluntaria, se considera que dos circunstancias - relacionadas, pero diferentes- pueden dar lugar a que esta exista. Una se presenta cuando el individuo no descubre los beneficios personales de participar de ese proyecto colectivo, de manera que no se apropia del mismo, y, por lo tanto, el éxito escolar o académico no constituye una meta personal. La violencia social en este caso residiria en la obligatoriedad escolar, y entonces el abandono es vivido como un acto de emancipación personal. La otra circunstancia supone que el sujeto no huye de una pauta impuesta, sino que necesita disponer de sí mismo y de sus tiempos para abocarse a otra meta personal que aparece como incompatible con esa oferta educativa. En este último caso, el abandono se debe a otra demanda vocacional.

La perspectiva personal es la que permite diferenciar estas situaciones y, por eso, la revisión de los testimonios personales de los desertores permitió descubrir en qué historias existió violencia social o institucional, es decir, exclusión académica por parte de escuelas y facultades, y en cuáles se trató de deserciones voluntarias.

La exclusión académica es una expresión de autoritarismo institucional que, al igual que otras modalidades de exclusión social, no 
requiere de ejercicio de fuerza externa, pues basta el poder simbólico de pautas de funcionamiento de la organización. Estas pautas sociales, que llegan a ser hegemónicamente aceptadas, se enseñan y aprenden por medio de acciones que constituyen violencia simbólica. Según Bourdieu (Bourdieu y Passeron, 1970), dicha violencia es el control cultural que ejercen las clases dominantes; es un sutil ejercicio de poder simbólico para imponer una definición del mundo social consistente con sus intereses. La cultura es así el vínculo mediador entre los intereses de la clase dominante y la vida cotidiana. Por consiguiente, son pautas sociales impuestas las que posibilitan excluir a un sujeto de un sistema - social y educativo- que está obligado a incluirlo.

Son acciones pedagógicas escolares y no escolares las que posibilitan esos aprendizajes y constituyen modalidades de violencia simbólica. Estas acciones pedagógicas, como muchas otras que sí pueden ser beneficiosas para el sujeto, también dan lugar a la adopción individual de formatos culturales a modo de habitus o capital cultural incorporado. De este modo, el habitus permite comprender la génesis de la articulación entre el funcionamiento social a nivel estructura -macro- con el nivel intrapersonal y de las interacciones sociales - micro-

Considerando estas categorias, en primer lugar, se describen los habitus auto obstaculizadores de los proyectos personales, identificados en los desertores. Dichos habitus frustraron a los protagonistas, ocasionando un dolor significativo. En segundo lugar, se reflexiona sobre los modos en que los desertores "cerraron" los procesos de abandono. Por último, se señalan las cuestiones del sistema -macro o estructurales-, que construyen los contextos institucionales violentos.

\section{Los habitus de los estudiantes}

Se identificaron las representaciones y pautas en relación con el ejercicio del propio rol, es decir, los habitus que regulan el comportamiento de los alumnos. Esto permitió encontrar cuatro habitus estudiantiles, que se describen a continuación. 
En primer lugar, el habitus estudiantil de someterse a pautas que reconocen como válidas. Los estudiantes entrevistados abandonaron sus proyectos de graduación en etapas avanzadas, porque se conformaron con las reglas de juego encontradas, aun cuando estas no les posibilitaban avances. Los relatos indican que, de todos modos, no existieron ni planteos ni intentos de los estudiantes dirigidos a modificar esas reglas. Esto muestra que existió conformidad, en tanto aceptaban la validez de metas y valores propuestos y también mecanismos para alcanzarlos.

Este habitus tiene dos expresiones: por un lado, la aceptación de presiones institucionales recibidas bajo el formato de intervenciones pedagógicas, y por otro, la naturalización de interferencias en varios planos de la vida personal.

En relación con esa primera expresión, los desertores de ambos niveles manifestaron pesar, incomodidad y sufrimiento a causa de las pautas supuestamente pedagógicas, a las que creían debían ajustarse. Según los niveles, había diferencias de formato, pero no de esencia. Los doctorandos identifican la intervención de sus directores de tesis como la principal causa de padecimientos y deserción, y hablan de un trato humillante y autoritario reiterado. Entre las pautas impuestas por el director estaba la elección del tema de tesis y la falta de real acompañamiento en la tarea; también relatan las presiones para publicar, la obligación de dar clases, el control de los tiempos individuales y la presión para cumplir plazos, así como la necesidad de hacer seminarios que consideraban "inútiles" en relación con sus intereses científicos y con el tema de tesis.

Los desertores de secundario encontraron frecuentemente docentes - profesores y directivos- que les gritaban y los avergonzaban públicamente con calificativos degradantes; refieren sobre docentes malhumorados que retaban y maltrataban indiscriminadamente a los alumnos; también acerca de profesores que se negaban a explicarles los contenidos no comprendidos o les demandaban dominio de otros que no les fueron previamente enseñados. Hablaban de profesores que "van y dan la clase", naturalizando que este modo de intervención 
docente - sin comunicación con estudiantes- es lo previsto en cuanto al ejercicio de ese rol. Pero además señalaron una circunstancia habitual: haber sido objeto de agresiones por parte de compañeros de curso, sin mediar intervención institucional para impedirlo o resolverlo. El formato habitual de los planes de estudio, que les demandaba la aprobación de cursos completos -o casi completos- para poder avanzar, los sometía a la frustración de tener que volver a acreditar espacios curriculares ya aprobados, cuando debian repetir cursos completos. En otros casos, eran condenados al "destierro escolar", porque se les negaba la reinscripción en la escuela y se forzaba así la pérdida de amigos, de arraigo y la necesidad de adaptarse a otra cultura escolar.

Los sujetos de ambas muestras se sintieron frecuentemente agredidos, incomprendidos, solos, avasallados y padecieron a causa de todo esto, sin embargo, no cuestionaron las reglas de juego, no lucharon contra ellas y si bien expresaron malestar, no así disconformidad con las normas. Los adolescentes se refieren a sus propias reacciones de descontrol frente a estas circunstancias como "ponerse rebeldes" en tanto no cumplian con las pautas. La rebeldia a la que aluden pasa por no responder según lo esperado, por no entrar a la escuela o escapar antes. Lo que se pone en cuestión es el tener que estar ahí, no el que la escuela funcione así. Por eso las deserciones son precedidas por inasistencias y rezago escolar, pero hasta bastante tiempo después no escapan de la situación. Tampoco le hacen frente en ninguno de los dos niveles, porque no organizaban ni individual ni colectivamente una resistencia dirigida a expresar cuestionamientos a esas pautas o a demandar cambios en las reglas de juego institucionales. En ambos niveles las padecen "sin chistar". Esto es así, porque en definitiva se trata de un habitus por el que se acepta que los integrantes de las comunidades educativas los "presionen", "castiguen" y "expulsen", naturalizando los formatos curriculares y las intervenciones docentes que los vehiculizan.

Hasta aquí las referencias a un habitus relacionado con las intervenciones pedagógicas, pero también se encontró una segunda expresión del habitus de sometimiento a las pautas impuestas: participar de la vida institucional naturaliza la interferencia en los distintos planos 
de la vida personal, como si se tratara de una organización total de tipo monacal que obligara a votos especiales. Obviamente que optar por una actividad académica supone destinar tiempo a la tarea, pero lo que se observa es que los estudiantes aceptaban con naturalidad renunciar a otras realizaciones, en algunos casos muy básicas, a causa del intento de cumplir con las pautas fijadas por la institución. Así, por ejemplo, formar una familia -tener hijos- aparece como meta incompatible con el cursado en ambos niveles; también las posibilidades de trabajar se ven comprometidas, y en el caso de los doctorandos, hasta la disponibilidad de tiempo para las comidas y la socialización con los compañeros de tareas. Para quienes no cuentan con becas elegir la carrera representa escoger privaciones de todo tipo, y esta no es una circunstancia de poco peso cuando se termina abandonando. Esta subordinación incondicional a la institución parece manifestación de la matriz eclesiástica de la escuela (Pineau, 2001).

El segundo habitus identificado es el reconocimiento -o asignación- de autoridad a quien ejerce el rol docente. Dicho reconocimiento consiste en la aceptación de la legitimidad del poder ejercido por otro. Si los estudiantes reconocen como legitimas las pautas impuestas y se someten a ellas, es porque creen en el derecho que tiene la institución en general, y sus docentes en particular, a imponer pautas que pueden desconocer sus necesidades y preferencias. Se pone así de manifiesto la asimetría en el vínculo docente-alumno, en un caso, y director-tesista en el otro, observada por Pineau (2001). Por esta razón, se acata, y por esta razón también lastima el trato que se recibe. Los muchos y distintos tipos de padecimientos que relatan los estudiantes son precisamente la prueba del reconocimiento sin cuestionamientos de esa autoridad, porque indican que se toma en serio todo juicio acerca del desempeño personal que provenga de ese docente o director; si no se le asignara credibilidad a ese juicio, no afectaría ni provocaría reacción.

El tercer habitus identificado es el de asumir la existencia de un rendimiento normal, que es un criterio externo determinado arbitrariamente por el rendimiento de otros, para la evaluación personal y, por lo tanto, también la naturalización de la necesidad de 
establecer competencia interpersonal como criterio de acreditación individual. Con expresiones diferentes, esto aparece en los dos niveles estudiados. En el nivel secundario, la oferta educativa ofrece un formato colectivo, que además supone masificación: para todos lo mismo, para todos igual. Tanto en lo que concierne a las intervenciones de enseñanza como a las de evaluación, la acción va dirigida al "alumno normal", al alumno típico esperado. En este nivel, los alumnos, si los compañeros de curso entendieron una explicación dada por el docente, ya no demandan nueva explicación porque se asume que hay una falta personal; si el docente da por aprendidos algunos contenidos porque compañeros del curso los dieron el año anterior, asumen que hay que conseguir quién los explique fuera de la escuela; se acepta abandonar la escuela porque hay alguna o algunas materias que otros aprueban, pero se piensa que uno mismo nunca logrará aprender, etc. Entre los doctorandos aparecen el señalamiento y el pesar ante un ambiente muy competitivo, en el que la meta es simplemente hacer más actividad académica acreditable que la que lleguen a hacer otros, porque este es el mecanismo para ser bien evaluado y alcanzar puestos. Es decir, el criterio de evaluación no se relaciona con el progreso personal sino con el rendimiento de otros, con la cantidad de competidores superados.

Las instituciones "educativas" parecen haber olvidado, incluso en los doctorados supuestamente personalizados, que el proceso tiene por protagonistas a sujetos siempre únicos en la combinación de necesidades, posibilidades e intereses y, por lo tanto, el criterio de valoración o evaluación del mismo debería ser el progreso personal, las diferencias evidenciadas entre un antes y un después. Sin embargo, las instituciones no funcionan así solo porque este sea el formato impuesto desde la docencia, sino también porque el alumnado asume que debe ser así. Estos comportamientos observados en los alumnos dan cuenta de que ellos naturalizan la existencia de una "normalidad de rendimiento" que funciona como criterio externo para las exigencias a las que deben adecuar el propio proceso educativo.

El cuarto habitus identificado es la consideración del abandono como una decisión o elección individual, lo que implica 
"desresponsabilizar" a la institución. Al naturalizar las reglas de funcionamiento institucional que no les permitían seguir los ritmos impuestos y alcanzar los resultados demandados, concluyen que lo inadecuado no es la oferta académica, sino la propia persona en el rol de alumno. Suponen que son ellos los dueños de la decisión; algunos llegan al desprecio de sí mismos y se culpan por haber perdido oportunidades dadas por la institución. La propia persona se convierte en el objeto del enojo, o bien, se conforman pensando que carecen de las condiciones necesarias para terminar.

\section{Deserción voluntaria y modos de cierre del abandono}

Se encontraron unos pocos casos de deserciones voluntarias vinculadas con sentir "otra vocación" no relacionada con el doctorado y la vida académica.

Así mismo, se identificaron cuatro modos de cierre del abandono por parte del resto de los desertores que se relacionaron con: 1) el doctorado realizado en otro país; 2) la búsqueda del bienestar; 3) la imposibilidad de procesar el abandono; 4) la ilusión de terminar.

\section{El doctorado realizado en otro pais}

El abandono en dos casos posibilitó la realización y culminación del doctorado en otro país y universidad. En cierto sentido, el abandono fue un recurso para superar la "experiencia doctoral insatisfactoria" sin obturar la vocación académica.

\section{La búsqueda del bienestar}

El abandono se concretó como una estrategia personal de sanación frente a un sistema que los hizo sufrir. En otros términos, se trató de una negación de la frustración. 
Este modo de cierre resultó una herramienta de resistencia fallida de los actores, que no les permitió permanecer en el sistema educativo y servirse de él, pero sí resguardar la propia salud mental poniéndose a salvo de un sistema social que les causó daño.

Los desertores que se ubicaron dentro de este modo de cierre no intentaron cambiar las circunstancias para que les fueran más favorables. No se enfrentaron; antes bien, huyeron en pos de resguardar su salud personal. No hubo afrontamiento sino evitación, lo que se asoció, en algunos casos, a la frustración por no lograr la meta educativa.

En el caso de los doctorados, la mayoría de los desertores mostraron una "aparente" resolución meditada de la decisión de abandonar. Algunos lo justificaron aceptando que el logro de las metas les requería más tiempo y otras experiencias. Otros señalaron que el doctorado no era lo que les interesaba o que identificaron mejor sus intereses y necesidades a largo plazo, así como las actividades ajustadas para satisfacerlas.

En ambos niveles se observó que estos desertores mostraron conformidad y estaban convencidos de abandonar porque quisieron. Dicha conformidad es el efecto de la violencia simbólica, y tal como señalan Bourdieu y Passeron (1970), agrega al poder de la fuerza social su propia fuerza simbólica. En la conformidad hay adhesión a la lógica imperante, hay aceptación de la legitimidad del orden vigente, por eso existe el convencimiento de que el abandono fue una decisión personal libremente tomada.

\section{La imposibilidad de procesar el abandono}

Hubo casos que no pudieron cerrar afectiva y efectivamente el proceso, entonces las heridas relatadas aparecieron con un grado de actualidad significativo. La situación de entrevista permitió revivir algunas de las situaciones dolorosas vinculadas con el abandono, y ponerlas en palabras, a veces por primera vez. Esto fue interpretado como un indicador de la ausencia de respuestas institucionales. Varios desertores 
tenian la "herida abierta" aun después de muchos años y sus relatos presentan lamentos, excusas y justificaciones frente al abandono.

Estos desertores no mostraron conformidad, sino dolor y enojo. La experiencia del enojo constituye el primer nivel de reacción, capaz de iniciar un camino de lucha por lograr mejores condiciones de vida personales y comunitarias. Si el enojo se vuelca sobre los que no tienen responsabilidad institucional para operar los cambios necesarios -compañeros de curso, profesores, etc.-, entonces es un desgaste de energías que no constituye resistencia, sino que aumenta la violencia no constructiva que circula y tiñe la vida institucional. Si el enojo no se articula con una adecuada lectura de la realidad, ni logra ningún cambio útil, con el tiempo pierde el impulso a la acción y se transforma en rencor, sentimiento de mayor estabilidad.

Se parte de que la violencia desplegada a través de una organización que opera mediante contenido cultural - escuela y doctorado-, es una modalidad vincular, intangible y simbólica, siempre hay un "otro" detrás, aunque no se lo identifique correctamente.

Entonces, la mayoría de los desertores tuvo episodios de enojo, o sea, una carga de agresividad que no fue útilmente canalizada en una resistencia capaz de oponerse a la reproducción social que supone la exclusión académica de los "no normales".

\section{La ilusión de terminar}

El abandono sirvió en algunos desertores para superar la frustración y conformarse con que terminarán el secundario o el doctorado en algún momento. Si bien no se realizó el seguimiento de las trayectorias posteriores, se considera que esta ilusión de finalizar operó como paliativo del dolor en quienes fueron expulsados del sistema educativo.

Estos cuatro modos de cierre del abandono muestran la compleja negociación por parte de los desertores entre motivaciones, expectativas, creatividad y la realidad tal como fue percibida por ellos 
-incluidas exigencias y limitaciones educativas e institucionales-. Los sujetos respondieron de manera diversa frente a ellas, tan es así que obstáculos similares dieron lugar a diferentes modos de cierre. No obstante, con excepción de unos pocos casos, la mayoría no dispuso de instancias de reflexión, junto con otros protagonistas, que posibilitaran el análisis institucional de las situaciones y un diseño de propuestas de continuidad para los interesados en ellas.

\section{Condicionamientos institucionales favorecedores del abandono}

\section{Restricción de la función educativa a mera instrucción}

Las intervenciones institucionales quedaban restringidas a funciones instructivas colectivas que se ofrecian en formatos uniformes. En la secundaria y el doctorado no existió seguimiento individual ni acompañamiento académico, motivacional o afectivo. La institución ignoraba la historia familiar y escolar previa, los acontecimientos actuales, las competencias e intereses estudiantiles, las frustraciones y desánimos; incluso en el nivel secundario, que recibe a un alumno afectivamente inmaduro y necesitado de protección. También era insuficiente la asistencia instructiva, ya que los sujetos necesitaban ayuda extraescolar para comprender contenidos y resolver las tareas escolares.

\section{Pesimismo pedagógico}

En ambos niveles hubo indicios de que los docentes no apostaron a intervenciones pedagógicas promotoras de capacidades no manifiestas en el alumno. Por el contrario, las mediaciones pedagógicas se centraron en la instrucción y la verificación de resultados para la acreditación. No se exploraron las posibilidades actuales de los estudiantes para descubrir y promover las potenciales. Resultó escaso el acompañamiento personalizado para el desarrollo de capacidades en el nivel secundario y también en el doctorado, aun cuando se trató de programas personalizados. 
Frente al pedido de ayuda para comprender un contenido expuesto en clase, una respuesta típica de los profesores de secundario fue "yo ya expliqué", respuesta que muestra que, ante la incomprensión, el docente consideraba que no había nada que pudiera hacer. Además, se encontró que las escuelas por propia cuenta - no por pedido de alumnos-, decidieron el pase a otra institución, lo cual también mostró la renuncia a nuevas intervenciones educativas con ese estudiante. Por su parte, los doctorandos también manifestaron sentirse solos frente a las tareas y no asistidos por los directores.

Con posterioridad a las instancias instructivas, los logros se controlaban a efectos de la acreditación. Incluso en procesos intelectuales tan complejos como son las elaboraciones de tesis, la intervención institucional se centró en el completamiento de listas de control y no en el acompañamiento para repensar las producciones.

En suma, estas prácticas docentes indicaron desconfianza en la educabilidad de los alumnos.

\section{Formato universal destinado al "alumno normal"}

La selección de los contenidos que se abordaban y la previsión de estrategias y tiempos de logros aparecía prefijada con independencia de las condiciones de quien iba a aprender. En el nivel secundario existían dos formatos -el común y el nocturno-y no una adecuación de las posibilidades a los tiempos y circunstancias reales de los sujetos.

Los contenidos no se vinculaban con las demandas cotidianas de los sujetos, es decir, ni con las inquietudes adolescentes en el secundario ni con los contextos profesionales en el doctorado, pues las pautas de la academia solo se vinculaban con la vida universitaria y se alejaban de los ámbitos de donde surgen y sobre los que se vuelcan los saberes. Los doctorandos se refirieron específicamente al "peligro de la burbuja". 
Tampoco se consideraban las reales disponibilidades de tiempos y ritmos para aprender de los alumnos. Las previsiones universales de plazos en el nivel secundario obligaban al cursado simultáneo de determinado número de asignaturas que, de no ser satisfactorio, determinaba el recursado de la totalidad, con la obligación de rehacer asignaturas ya acreditadas. Recursar conlleva rezago, frustración, pérdida de compañeros y cambios de escuela, lo que constituyó un importante factor de desánimo y una antesala del abandono. Los ritmos previstos, con independencia de las posibilidades individuales, especialmente en los doctorados, condicionaban el despliegue de aspectos vitales básicos -formar familia, recreación, actividad laboral, etc.-.

En suma, las ofertas suponían un "alumno normal" que en el nivel secundario diurno sería semejante a los adolescentes de clase media, y en los doctorados, a los profesionales becados capaces de vivir en actitud de entrega exclusiva para su formación académica.

\section{Con instructores y sin maestros}

Los alumnos eran los convidados de piedra, invisibles. Los docentes -profesores, directivos y directores de tesis- casi no los registraban en sus necesidades y particularidades. El rol docente perdía su esencia de educador y "maestro", porque no alentaban ni seguían las inquietudes de quien estaba para aprender. Eran instructores y evaluadores en procesos normalizados. Se perdía de vista la esencia de lo que es la educación en tanto proceso personal de promoción humana, y la esencia del acto de educar como amorosa comunicación interpersonal.

\section{Un campo con funciones de aparato}

En el campo escolar y académico, como en todo campo de la vida social (Bourdieu y Wacquant, 2005) el poder logrado en distintos puestos, queda custodiado por las reglas de juego. Así los tesistas eran una especie de empleados al servicio del currículum del director y de sus proyectos de investigación y de cátedra, a la vez que se ejercían 
presiones dirigidas a limitar posibilidades e impedir el acceso de los que potencialmente amenazaban privilegios y lugares. La beca era un recurso del que se servian los directores para generar dependencia en los doctorandos y para excluir a los que trabajaban. Existió aquí la paradoja del sometimiento donde deberia reinar la autonomía del pensamiento para producir conocimiento. Los tesistas estaban alienados, pues dejaban de ser dueños de sus trabajos.

En la secundaria, el poder también se ejercía sin consideración de los intereses -necesidades y preferencias-de los estudiantes; así, los despliegues instructivos de los docentes no debian ser interferidos por las incomprensiones o inquietudes de los adolescentes, que además debían someterse a gritos y amenazas de ser reprobados ante cualquier interferencia en el orden impuesto.

En este campo hay un capital cultural valorado en juego, que justifica las reglas; en este caso se trata de capital científico y pautas de la academia. Los contenidos a transmitir o investigar, seleccionados con independencia de los destinatarios, muestran que se trataba de organizaciones al servicio de la cultura a conservar o producir, y no de las personas en formación. Aunque de todos modos la selección de contenidos tampoco respondía a intereses de un proyecto social más amplio, porque solian tener justificaciones autorreferenciales. Así, en la secundaria solian enseñarse contenidos solo vigentes dentro de las escuelas y desvinculados del contexto cultural. Mientras que en los doctorados sus programas de investigación solían desvincularse de las políticas científicas del contexto.

En un campo social hay luchas por el capital, las reglas de juego y la distribución de poder entre los puestos; pero en estos casos solo había custodia; las luchas parecen haber cesado, las pautas y significaciones se imponian atendiendo a intereses que no eran los de los alumnos y ellos se conformaban con esas significaciones y las integraban en sus habitus estudiantiles. La hegemonía construida, habilita a pensar que funcionaban como aparatos (Bourdieu y Wacquant, 2005) en los que se acallaban las resistencias. 


\section{Conclusiones}

- El abandono educativo no es un episodio aislado, es un momento dentro de un proceso que articula varias intervenciones, una sumatoria de condiciones y acontecimientos diversos. Existe un "desenganche" progresivo que se produce tras frustraciones varias. Paulatinamente, los estudiantes dejan de intentar progresos, de interesarse, de esperar. El abandono llega cuando las energías fueron definitivamente puestas en función de otras metas.

- El abandono está invisibilizado. El sistema educativo niega, encubre, minimiza, no quiere verlo. Prueba de ello son la inexistencia de listados de los desertores, así como la escasez de investigaciones y de políticas de retención estudiantil.

- El abandono es, predominantemente, un producto de la exclusión académica. La reflexión a partir de los casos analizados lleva a la conclusión de que ella predominó, mientras que la deserción voluntaria fue excepcionalmente hallada. En todos los casos estudiados, tanto de secundaria como de doctorado, se desplegaron todas las estrategias al alcance individual, incluso intentar varios años a pesar de obstáculos institucionales, postergaciones personales y efectos nocivos en la salud mental. Las instituciones carecen del "ethos de cuidado" necesario.

- La existencia de demarcaciones según criterios externos de resultados esperables, es un rasgo de autoritarismo institucional, porque supone un funcionamiento desvirtuado e ilegítimo, que no está respaldado en una justificación ética.

El derecho a imponer pautas de participación a los individuos ubicados en rol de estudiantes está dado por el tipo de competencia que el nivel otorga. La educación es un proceso personal, vinculado con la vida privada de quien lo experimenta; por ello, existe derecho externo a regirlo, solo si el efecto puede incidir negativamente en la vida de terceros. Desde esta perspectiva, la escuela secundaria prepara para la convivencia social armónica, y por esta competencia, existe derecho 
a intervención heterónoma. Pero los otros contenidos del proceso deberian corresponderse con las inquietudes y capacidades personales de quien se educa. Del mismo modo, el ejercicio de una profesión sí constituye un modo de intercambio social, se vincula con la convivencia y justifica intervención heterónoma, sin embargo, el doctorado ofrece un campo de especialización y no una profesionalización, por lo que está vinculado con el interés personal y no con el social. En otros términos, los casos en estudio no corresponden a formaciones que habiliten para el ejercicio profesional, por ello, no se justifica que los contenidos propuestos y los ritmos de trabajo demandados surjan de imperativos externos.

Sin embargo, este rasgo de autoritarismo institucional está absolutamente naturalizado y logra conformidad tanto en sus funcionarios como en quienes padecen sus consecuencias.

\section{Referencias}

Barsky, O. (1997). Los posgrados universitarios en la República Argentina. Troquel: Buenos Aires.

Barsky, O. (1999). El desarrollo de las carreras de posgrado. En E. Sánchez Martínez (Ed.), La educación superior en Argentina. Transformaciones, debates, desafios (pp. 126-150). Buenos Aires: Ministerio de Cultura y Educación.

Barsky, O., Sigal, V. y Dávila, M. (2004). Los desafios de la universidad argentina [A. Menegotto, Trad.]. Buenos Aires: Siglo XXI Editores.

Bartolini, A. (2013). Persistencia y desgaste doctoral. Un estudio en ciencias de la educación y en ciencias experimentales (Tesis doctoral). Universidad de San Andrés, Buenos Aires, Argentina.

Becher, T. (2001). Tribus y territorios académicos. La indagación intelectual y las culturas de las disciplinas. Barcelona: Editorial Gedisa. 
Bourdieu, P. y Passeron, J.C. (1981). La reproducción. Elementos para una teoría del sistema de enseñanza. Barcelona: Laia.

Bourdieu, P. y Wacquant, L. (2005). Una invitación a la sociología reflexiva [A. Dilon, Trad.]. Buenos Aires: Siglo XXI Editores.

Bowen, W. y Rudenstine, N. (1992). In Pursuit of the Ph.D. New Jersey: Princeton University Press.

Carlino, P. (2005). La experiencia de escribir una tesis: contextos que la vuelven más difícil. Anales del Instituto de Lingüistica, XXIV, 41-62.

Chaves, M. (2009, junio). Papeles de trabajo. Revista Electrónica del Instituto de Altos Estudios Sociales de la Universidad Nacional de General San Martín, 2(5): 1-111.

De Souza Minayo, M. C. (2009). La artesania de la investigación cualitativa [V. Martinovich, Trad.]. Buenos Aires: Lugar.

Del Bello, J.C., Barsky, O. y Giménez, G. (2007). La universidad privada argentina. Buenos Aires: Zorzal.

Dussel, I. (2004). Desigualdades sociales y desigualdades escolares en la Argentina de hoy. Algunas reflexiones de hoy [Documento preparado para el Ministerio de Educación de la Nación]. Facultad Latinoamericana de Ciencias Sociales (FLACSO), Sede Argentina. Recuperado de http://bibliotecavirtual. clacso.org.ar/ar/libros/argentina/flacso/dussel.pdf

Ehrenberg, R. G., Zuckerman, H., Groen, J. A. and Brucker, S. M. (2010). Educating Scholars: Doctoral Education in the Humanities. New Jersey: Princeton University Press.

Escudero Muñoz, J. M., González González, M. T. y Martínez Domínguez, B. (2009). El fracaso escolar como exclusión educativa: comprensión, políticas y prácticas. Revista Iberoamericana de Educación, 50, 41-64. 
Fernández Lamarra, N. (2003). La educación superior en debate: situación, problemas y perspectivas. Buenos Aires: Eudeba.

Garcia de Fanelli, A.M. y Jeppesen, C. (Coords.). (2004). La oferta de carreras de doctorado en la Argentina [Trabajo preparado para la Comisión de Gestión de Recursos Humanos de la SECYT]. Mimeo.

Gerlo, G. (2014). Hacia la comprensión del doloroso proceso de construcción de deserción de la escuela secundaria en adolescentes de las clases bajas de Paraná (Tesis de Maestría). Universidad Nacional de Entre Ríos, Paraná, Entre Ríos, Argentina.

Instituto Nacional de Estadística y Censo. (2010). Censo Nacional de Población, Hogares y Viviendas. Recuperado de http:/ /www.indec.mecom.ar

Jeppesen, C., Nelson, A. y Guerrini, V. (2004). Diagnóstico y perspectiva de los estudios de posgrado en Argentina. En La educación superior en Argentina (Vol. 2). Buenos Aires: Secretaría de Políticas Universitarias, Ministerio de Educación, Ciencia y Tecnología de la República Argentina - IESALC/UNESCO.

Krotsch, P. (2003). Educación superior y reformas comparadas. Buenos Aires: Universidad Nacional de Quilmes Editorial.

Marquís, C. y Toribio, D. (2006). Capitulo sobre la Argentina. En Informe sobre la educación superior en Iberoamérica. Recuperado de http://www.cinda.cl/ download/informes_nacionales/argentina.pdf

Pérez Lindo, A. (2007). Prospectiva de la Educación Superior Argentina 2020. En Secretaría de Ciencia y Tecnología, Plan Estratégico Nacional de CTI "Bicentenario" (2006-2010), ejercicio 2020: escenarios y estrategias del CTI. Grupo Educación Superior. Mimeo.

Peyrú, G. y Corsi, J. (2007). Violencias sociales. Autoritarismo y abuso de poder: epidemias del siglo XXI. Buenos Aires: Editorial Ariel.

Pineau, P. (2001). La escuela como máquina de educar. Tres escritos sobre un proyecto de la modernidad. Buenos Aires: Editorial Paidós. 
Poggi, M. y Tenti Fanfani, E. (2009). Abandono escolar y politicas de inclusión en la educación secundaria. Buenos Aires: Programa Naciones Unidas para el Desarrollo (PNUD).

Tinto, V. (1989). Definir la deserción: una cuestión de perspectiva (C. M. de Allende, Trad.). Revista de la Educación Superior, 71, 33-51.

Tinto, V. (1993). Leaving College. Rethinking the Causes and Cures of Student Attrition. Chicago and London: The University of Chicago Press.

\section{Cómo citar este artículo}

Bartolini, A. M. y Gerlo, G. (2017). Reflexiones sobre experiencias de abandono de escuela secundaria y doctorado en Argentina. Modos de cierre y condicionantes individuales e institucionales. Universitas Humanistica, 83, 85-108. http:// dx.doi.org/10.11144/Javeriana.uh83.reae 